\title{
EVALUATION OF SUBSURFACE DAMAGE IN CFRP FOLLOWING BALLISTIC IMPACT BY IR THERMOGRAPHIC METHOD
}

\author{
W. Swiderski \\ Military Institute of Armament Technology, 05-220 Zielonka, Poland \\ Presenting and Corresponding Author: waldemar.swiderski@wp.pl
}

\begin{abstract}
This paper presents an evaluation of the areas of internal material damage caused by penetration by projectile of a sample of carbon fibre reinforced plastic (CFRP). The proposed method, which registers changes of temperature via thermal cameras on both sides of the sample under destructive testing, can complement the standard test methods conducted according to STANAG 2920. It also negates the need for further ballistic testing in an already damaged area of the material. The results were verified by non-destructive pulsed thermography testing, which is often used in tests of multilayer composite structures.
\end{abstract}

KEYWORDS: IR camera, CFRP, Distractive testing, Ballistic limit, Pulsed thermography,

\section{INTRODUCTION}

Among the many necessary properties of composite materials in both civilian and military applications, the most important are: low specific weight associated with high specific stiffness and strength, high corrosion resistance, good crack resistance and high resistance to local damage. [1] In military applications, multi-layer fibre-reinforced composite materials (laminates) are often used. The most common are carbon, glass and aramid fibres. One military application in which multi-layered fibre-reinforced composite structures are used is light ballistic armour. Their design should also take into account the impact resistance of the material. The area of destruction of the material surrounding the point of impact is very often several times larger than calibre of the projectile or fragment; this information is important when considering the possible repair of the damaged portion of the armour as the surrounding area may not provide adequate protection in subsequent impacts. [2] The standard test for puncture resistance of the armour is by the destructive testing method STANAG 2920 [3]; that is, the determination of the $\mathrm{V}_{50}$ ballistic limit by means of a projectile that simulates a fragment of $1.1 \mathrm{~g}$ weight (standard fragment as specified by Polish standards). This test does not specify the zone of destruction around the point of impact. The aim of the tests described in this paper was to determine the zone of destruction within the armour material by a non-destructive testing method during a destructive $\mathrm{V}_{50}$ test.

\section{EXPERIMENTAL TESTING}

Tests were carried out on two samples, one from a single plate made of carbon fibre and a second in which two plates were bonded with epoxy resin. The carbon fibre plates had the same dimensions of 350x150x1 mm. An air gun was used to shoot lead and steel projectiles with the energy outlet of the bullets below 17J. During impact, changes in the temperature fields on both the surface impacted by the projectile and the rear surface were recorded by two thermal cameras. The thermal camera on the impacted surface was positioned such that the camera axis was perpendicular to the sample surface. The axis of the thermal camera on the rear of the sample was directed at an angle of $60^{\circ}$ to the sample surface so that the projectile could not damage the camera lens if it punctured the sample. Fig. 1 shows the thermogram recorded on impacted surface after shoot lead pojectile. In order to verify and compare the results from the thermal cameras, after the ballistic testing, non-destructive testing of the samples was carried out via pulsed thermography using a heat lamp with a power $2 \mathrm{~kW}$ (heating time $5 \mathrm{~s}$ ) and thermal camera FLIR SC 7600. The tests were performed using both reflection and transmission approaches for the front (impacted) and the rear surfaces. Example of the thermal image obtained from this tests is presented in Figure 2. 
http://dx.doi.org/10.21611/qirt.2017.019

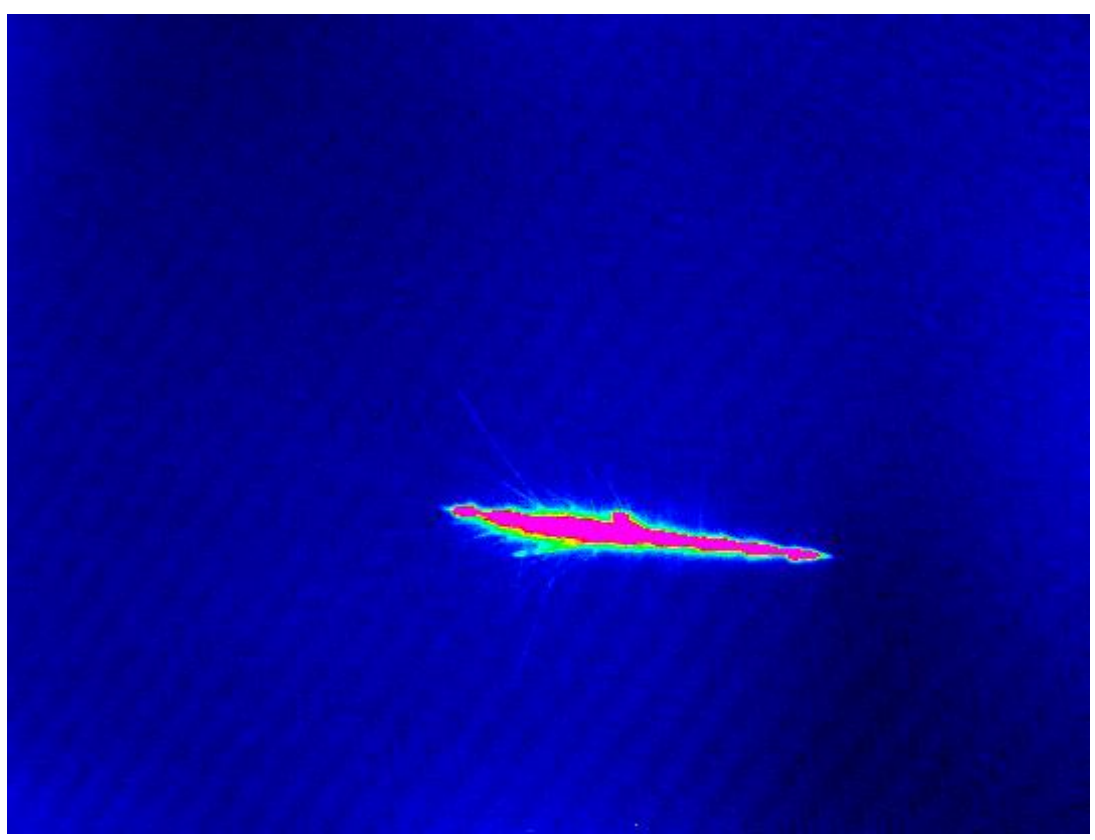

Fig. 1 Thermogram of single plate after shoot lead projectile.

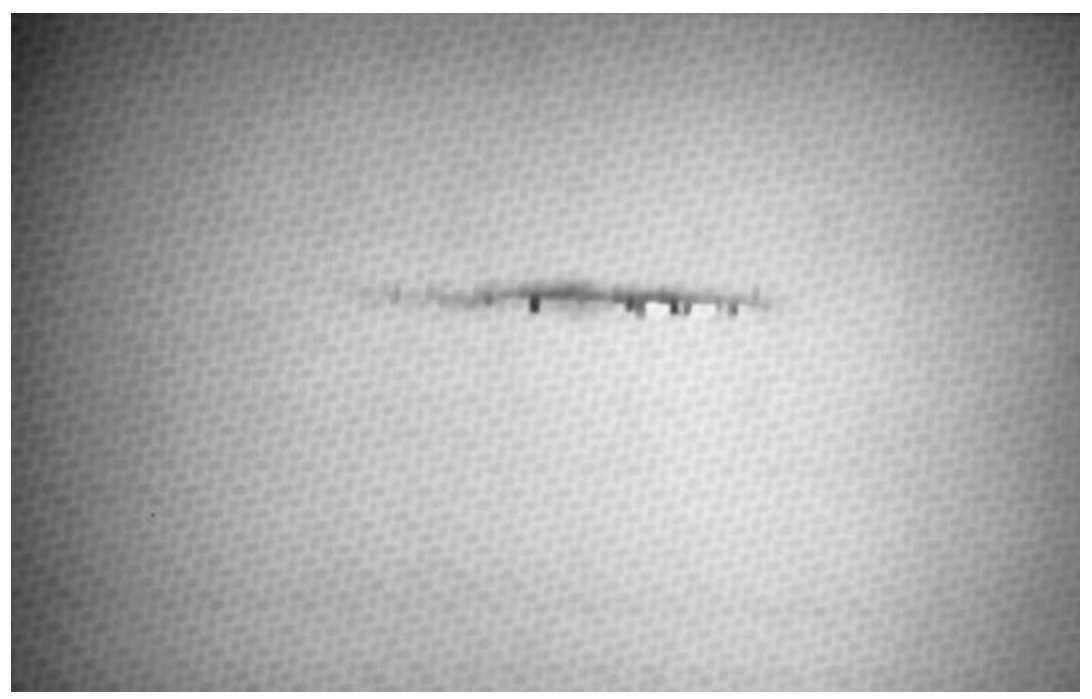

Fig. 2 Thermogram of single plate after shoot lead projectile (transmission approach).

\section{CONCLUSIONS}

The tests using infrared cameras have shown that it is possible to determine the area of destruction of the internal structure of the composite carbon fibre reinforced plastic during destructive ballistic testing.

Future work will focus on the testing of composite structures with more layers and reinforced with glass and aramid fibres during ballistic testing in accordance with STANAG 2920.

\section{REFERENCES}

[1] A. Muc, Mechanics of fibrous composites, 2003, in Polish

[2] W. Swiderski, M. Pracht, Ultrasonic IR thermography detection of defects in multi-layered aramide composites, Proc. of 19th World Conference on Non-Destructive Testing 2016.

[3] STANAG 2920 Ballistic test method for personal armour. 